\title{
Embryonation and Infectivity of Ascaris suum Eggs. A Comparison of Eggs Collected from Worm Uteri with Eggs Isolated from Pig Faeces
}

\author{
By A. Oksanen, L. Eriksen, A. Roepstorff, B. Ilsøe, P. Nansen and P. Lind \\ College of Veterinary Medicine, Helsinki, Finland, and \\ Royal Veterinary and Agricultural University, Denmark.
}

\begin{abstract}
Oksanen, A., L. Eriksen, A. Roepstorff, B. Ilsee, P. Nansen and P. Lind: Embryonation and infectivity of Ascaris suum eggs. A comparison of eggs collected from worm uteri with eggs isolated from pig faeces. Acta vet. scand. 1990, 31, 393-398. - Ascaris suum eggs were collected from pig faeces or dissected from worms obtained from the same pigs. Eggs from the two sources were allowed to embryonate in $0.1 \mathrm{~N} \mathrm{H}_{2} \mathrm{SO}_{4}$, in $1 \%$ buffered formalin or in tap water. The embryonation of the sulphuric acid and water cultures occurred at the same speed, while the formalin cultures developed slightly more slowly. By experimental inoculation of helminthfree pigs and subsequent counting of white spots in the livers and larvae in the lungs day 7 p. i., the infectivity of eggs dissected from worm uteri and embryonated in sulphuric acid (a normal laboratory procedure) was compared with that of eggs collected from faeces and embryonated in water (i.e. more naturally developed eggs). The results suggest that the two types of eggs were equally infective. For this reason the common practice of using Ascaris eggs dissected from worms for experimental infections might be acceptable.
\end{abstract}

egg culture; white spots; larvae; lungs; baermannization.

\section{Introduction}

Experimental infections with the large roundworm Ascaris suum are most often performed on the basis of eggs collected from the uteri of worms obtained from slaughtered pigs (Andersen et al. 1973, Jorgensen et al. 1975, Eriksen et al. 1980, Urban et al. 1988). This is the most simple procedure for obtaining large numbers of eggs in a clean suspension. The eggs are then embryonated in either $0.1 \mathrm{~N}$ sulphuric acid or another medium that inhibits microbial growth. Eggs can also be harvested from the faeces of infected pigs. A refined method to obtain highly concentrated egg suspensions from large volumes of faeces has been described by Jorgensen (1978). However, a main drawback is that this procedure is rather laborious.

It is often questioned, whether eggs harvested from worm uteri may exhibit a normal course of embryonation and achieve full infectivity, since such eggs are not fully developed with regard to the composition of the outer albuminous shell layer (Enigh \& Dey-Hazra 1976) and possibly other characteristics acquired during the normal oviposition and subsequent passage through the intestinal tract of the host.

To answer these questions and to determine whether eggs dissected directly from worms can be recommended for experimental purposes, 2 experiments were performed. The first was designed to examine the embryona- 
tion of $A$. suum eggs from the 2 sources in different culture media. The second experiment was made to compare the infectivity of fully embryonated eggs from the 2 sources.

\section{Materials and methods}

From a farm with a known high prevalence of $A$. suum, 7 fattening pigs were selected. Faeces was collected over a period of a few days and then stored at $4^{\circ} \mathrm{C}$. The pigs were subsequently slaughtered, and all adult female worms $(\mathrm{N}=37)$ were collected from the intestines, rinsed in tap water and stored overnight at $4^{\circ} \mathrm{C}$.

To enable a proper comparison of methods, it was ensured that all the eggs originated from the same worms, i.e. either normally passed with faeces or dissected from the worms when isolated at the time of slaughter.

\section{Embryonation experiment}

A. Eggs embryonated from feaces. One kilogram of pooled faeces was suspended in 101 of water, after which it was sieved through a series of laboratory sieves consisting of $190 \mu \mathrm{m}, 115 \mu \mathrm{m}$ and $25 \mu \mathrm{m}$ apertures, respectively. The material retained on the $25 \mu \mathrm{m}$ sieve was washed with tap water, collected in $100 \mathrm{ml}$ centrifuge tubes, allowed to settle in water and subsequently flotated 3 minutes at centrifugation by $2500 \mathrm{rpm}$ in a sucrose solution $(550 \mathrm{~g} / \mathrm{l})$. The surface layer was collected with a pipette and washed 4 times by repeated centrifugations in tap water. The present method employed only 1 quick flotation, which was thought to be preferable, because it can not be entirely excluded that effects of osmotic pressure might influence the viability of eggs. However, there is no available literary evidence to suggest this.
B. Eggs isolated from worm uteri. The worms were dissected and the distal 2.5-4 $\mathrm{cm}$ of their uteri were cut off and rinsed in tap water. The pieces of uteri were then cut in 2-3 mm long sections with a pair of scissors. The suspension of tissues and eggs was pressed through a $190 \mu \mathrm{m}$ laboratory sieve and left to settle in water in a large glass jar for $30 \mathrm{~min}$. The supernatant was removed The normal procedure was followed by removing the outer albumin layer in order to prevent the eggs from clustering and adhering to surfaces (Eriksen 1981). This was obtained by bleaching them for $10 \mathrm{~min}$ in a $0.5 \%$ sodium hypochlorite solution under continuous stirring by a magnetic stirrer. Subsequently, the eggs were allowed to settle for $30 \mathrm{~min}$ in the same solution. They were then washed several times by allowing them to settle in tap water to remove any excess hypochlorite.

C. Procedure of cultivation and examination. A total of 6 cultures were prepared, 3 with eggs of faecal origin (a1, a2, and a3) and 3 with eggs collected from uteri (b1, b2, and b3). The egg batches were suspended in 3 different media according to the following scheme: al and bl. Eggs suspended in $0.1 \mathrm{~N} \mathrm{H}_{2} \mathrm{SO}_{4}$. a2 and b2. Eggs suspended in $1 \%$ buffered formalin.

a3 and b3. Eggs suspended in tap water.

All cultures were prepared to contain 5,000-10,000 eggs per $\mathrm{ml}$, because a high density (more than 25,000 eggs per $\mathrm{ml}$ ) has been observed to inhibit embryonation (Eriksen 1987). The cultures were stored in $18 \mathrm{~cm}$ diameter Petri dishes in a thermostat at $25^{\circ} \mathrm{C}$. The depth of suspensions was adjusted to $3 \mathrm{~mm}$. Aeration was provided by opening the lids for $15 \mathrm{~min} 3$ times weekly. 
If evaporation seemed to have reduced the liquid volume with more than $25 \%$, distilled water was added. The rate of embryonation was observed once a week by microscopical examination of a sample of 100 eggs. Egg samples from cultures of faecal origin were bleached in $5 \%$ sodium hypochlorite for 5 min prior to the microscopical examination to enable better study of the eggs' inner structures.

Examined eggs were grouped into the following categories:

Abnormal eggs = infertile, degenerated and other eggs obviously unable to develop into infective stage.

Pre-larval stage eggs = apparently normal eggs, where larvae were not yet distinguishable.

Ll stage eggs = eggs containing a distinguishable first stage larva (not necessarily fully developed).

L2 stage eggs = eggs containing a second stage larva (apparently infective eggs).

After completion of the embryonation experiment, the cultures were feft in the thermostat for an additional 2 weeks after which they were considered to have reached their maximal infectivity (total cultivation time was 50 days). Subsequently, 2 of the batches were used in infectivity tests (see below).

\section{Infectivity experiment}

Twenty Danish Landrace/Yorkshire crossbreed pigs, 9 to 10 weeks old and bodyweights of approximately $25 \mathrm{~kg}$, with no previous evidence of helminth infection, were obtained from a research station. Prior to inoculation, blood and faecal samples were collected from each individual pig to reveal any possibility of recent infection. The sera were analyzed using an ELISA technique with excretory/secretory (ES-) antigen from $\mathrm{L}_{2}$-larvae $(1 \mu \mathrm{g} / \mathrm{ml})$ as coating antigen and swine serum (diluted 1:1000) and Horse-radish peroxidase-labelled Rabbit-anti-Swine Immunoglobulin (diluted 1:10000). Positive reference-sera originated from a known Ascaris exposed herd. Faecal egg counts were made according to a modified McMaster method with a sensitivity of 50 eggs per gram (epg).

The pigs were allocated into 2 comparable groups (A and B) according to sex and litter origin. They were inoculated using a stomach tube. Pigs of group A each received 5000 fully embryonated eggs of culture a3, i.e. simulating infection with natural eggs and pigs of group B were inoculated with 5000 fully embryonated eggs of culture b1, i.e. following the procedure normally used by many authors (Kelley et al. 1965, Ferguson et al. 1968, Eriksen 1981). Prior to inoculation, $10 \mathrm{egg}$ counts were made of each thoroughly mixed culture in order to accurately check the inoculation doses.

The pigs were given commercial feed according to a standard feeding scheme and the 2 groups were kept in separate comparable pens in a parasite-free housing unit.

Seven days post inoculation (p.i.), all pigs were slaughtered. White spots on both the visceral and parietal liver surface were counted separately. Using a kitchenware blender with sickle blade (Philips HR 2376 Electronic) the livers were minced for approximately $15 \mathrm{~s}$ and the lungs for approximately 25 sec resulting in tissue pieces having an average size of $1-2 \mathrm{~mm}$. Subsequently, the tissue pieces of each organ were baermannized in 101 of $0.9 \%$ saline containing 1 million I.U. of potassium benzylpenicillin (Novocillin vet.) and $1 \mathrm{~g}$ of dihydrostreptomycin sulfate (Dihydrostreptomycin vet.) to prevent bacterial growth, which might otherwise interfere with the microscopical recovery of larvae. The baermannization was performed for $20 \mathrm{~h}$ in a heated room (ap- 
proximately $35^{\circ} \mathrm{C}$ ). A volume of $20 \mathrm{ml}$ from the bottom of each apparatus funnel was collected in separate plastic jars and Lugol's solution was added to kill eventual microbes and to stain the larvae. With regard to the lung samples the total volume was examined under a stereoscope, but only $10 \%$ samples of the total volume of the liver fluid was examined (due to the time consuming search for larvae in the cloudy suspension).

The differences between the mean numbers of white spots as well as the mean larval counts of the 2 groups were tested using Student's t-test (two-tailed).

\section{Results}

The first apparently fully embryonated eggs (2nd stage larva) were seen in all cultures 3 weeks after the start of cultivation. Subsequently, the proportion of apparently fully embryonated eggs did not increase. The lowest percentage of embryonation (88\%) were seen in formalin cultures a 2 and b2, while other cultures reached a 90-97\% embryonation level. Embryonation of the respective egg cultures is described in Fig. 1.

No feacal samples of the experimental pigs contained any detectable eggs. None of the
Table 1. The proportion (\%) of apparebtly infective $\left(L_{2}\right)$ eggs in the respective egg cultures 3 , 4 and 5 weeks after the start of the cultivation at $25^{\circ} \mathrm{C}$.

\begin{tabular}{lccc}
\hline & \multicolumn{3}{c}{ Weeks } \\
\cline { 2 - 4 } Culture & 3 & 4 & 5 \\
\hline a1 (faeces $\left./ \mathrm{H}_{2} \mathrm{SO}_{4}\right)$ & 86 & 90 & 88 \\
b1 (uteri/h $\left.\mathrm{h}_{2} \mathrm{SO}_{4}\right)$ & 92 & 94 & 95 \\
a2 (f./formalin) & 82 & 88 & 85 \\
b2 (u./formalin) & 83 & 87 & 88 \\
a3 (f./ $\left./ \mathrm{H}_{2} \mathrm{O}\right)$ & 91 & 94 & 91 \\
b3 (u. $\left./ \mathrm{H}_{2} \mathrm{O}\right)$ & 96 & 97 & 94 \\
\hline
\end{tabular}

sera showed specific antibodies to Ascaris larval secretion, thus no indication of previous infection was found in the experimental pigs.

The white spots in the livers were typically reticulate. The numbers of white spots as well as the numbers of larvae recovered from the lungs are presented in Tables 1 and 2 . For both parameters, there was a rather large variation between individuals. Variation between the groups was statistically insignificant $(p>0.05)$ by the t-test. No larvae were found in any of the liver samples.

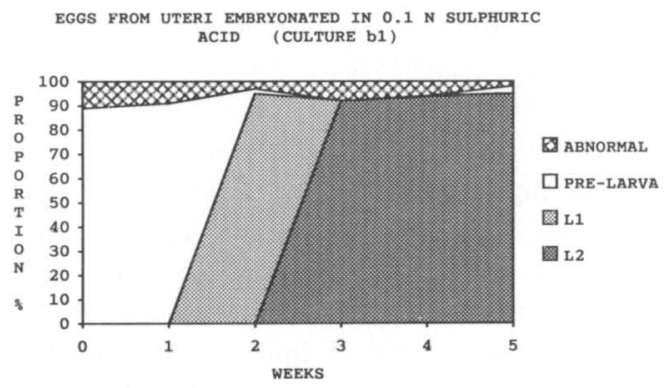

Figure 1. Development of egg cultures subsequently used in the infection experiment. The proportion (\%) of eggs embryonated in each stage according to weekly examinations.

ABNORMAL = infertile, degenerated and other eggs obviously unable to develop further.

PRE-LARVA = apparently normal eggs; larva not yet distinguishable.

L1 = eggs containing a first stage larva.

L2 = eggs containing a second stage larva (apparently infective). 
Table 2. The average number ( \pm s.d.) of white spots on respective liver surfaces in the 2 groups of inoculated pigs - day 7 p.i.

\begin{tabular}{lcccc}
\hline & & \multicolumn{3}{c}{ Liver surface } \\
\cline { 3 - 5 } Group & $\mathrm{N}$ & parietal & visceral & both \\
\hline A & 91 & $232 \pm 82$ & $167 \pm 74$ & $398 \pm 153$ \\
B & 10 & $245 \pm 111$ & $173 \pm 90$ & $417 \pm 196$ \\
\hline A+B & 19 & $238 \pm 96$ & $170 \pm 80$ & $408 \pm 172$ \\
\hline
\end{tabular}

Group $A=$ pigs inoculated with eggs from faeces. Group $B=$ pigs inoculated with eggs from worm uteri.

1 The data of one pig had to be omitted, because after slaughter it was diagnosed to have shipping fever (Glaesser's disease) which caused fibrinous coating on the liver and this made it impossible to distinguish white spots.

Table 3. The average number ( \pm s.d.) of larvae recovered from the lungs of the inoculated pigs day 7 p.i.

\begin{tabular}{llc}
\hline Group & $\mathrm{N}$ & Larvae recovered \\
\hline A & 10 & $2316 \pm 490$ \\
B & 10 & $2490 \pm 421$ \\
\hline A+B & 20 & $2403 \pm 453$ \\
\hline
\end{tabular}

\section{Discussion}

Towards the end of the embryonation period there was a slightly higher proportion of abnormal eggs and hence a lower embryonation rate in the formalin cultures than in other cultures. This difference may be due to the disintegration of infertile eggs that was noticed to take place in the water culture b3. On the other hand, Beer (1973) noticed that the embryonation of Trichuris suis eggs was retarded in solutions of $1-5 \%$ formalin; the eggs starting to degenerate in the morula stage. However, differences in the final embryontion rates in the present study were small.

Fairbairn (1960) reported that in vitro hat- ching of Ascaris eggs was strongly dependent on the conditions under which the eggs were embryonated. The hatching of eggs embryonated in $1 \%$ formaldehyde or $2 \%$ sodium dichromate solutions was reduced to $25 \%$ and $2 \%$, respectively, of the hatching rate of eggs embryonated in $0.1 \mathrm{~N}$ sulphuric acid. Whether hatching of eggs embryonated in formalin or dichromate solutions is prevented also in the gut, is unknown.

The numbers of larvae recovered at 7 days p.i. from the lungs of inoculated pigs were generally high. Urban et al. (1988) found 7 days p.i. lung recoveries of $15-20 \%$ in 10,000 eggs infections, compared with our average figures of $45-50 \%$ in $5,000 \mathrm{egg}$ infections (Table 2). As no larvae were recovered from the livers, it is probable that the vast majority of viable larvae had already left the livers and reached the lungs at the time of autopsy. Yet, the baermannization fluid of the livers was very thick and opague due to liver cells. This caused difficulty when examining the samples and it is possible that a small number of larvae was overlooked.

Sodium benzylpenicillin has been reported to act as a GABA neurotransmitter antagonist in Ascaris (Martin 1981). This antagonism did not prevent a good larval recovery rate in the present study. Apparently, the concentration used (100 I.U. of potassium benzylpenicillin per $\mathrm{ml}$ ) did not influence the larvae negatively. Because of the inhibition of bacterial growth, the larvae from the lungs were easy to identify and convenient to count.

Finally, it is reasonable to conclude that eggs isolated from worm uteri and subsequently allowed to embryonate in $0.1 \mathrm{~N}$ sulphuric acid are fully comparable with "normal" eggs embryonated in water, with regard to the course of experimental infections. 


\section{Acknowledgements}

This study was made possible by grants from the Lundbeck Foundation, Nordic Council for Agricultural Research (Grant No. 59) and Danish Agricultural and Veterinary Research Council (Grant No. 5.23.99.02). Skilful technical assistance was given by Annette Pedersen, Lotte Nicolaisen and Niels Midtgaard.

\section{References}

Andersen $S$, Jorgensen RJ, Nansen $P$, Nielsen $K$ : Experimental Ascaris suum infection in piglets. Inverse relationship between the numbers of inoculated eggs and the numbers of worms established in the intestine. Acta pathol. Microbiol. Scand., Sect. B. 1973, 81, 650-656.

Beer RJS: Studies on the biology of the lifecycle of Trichuris suis Schrank, 1788. Parasitology 1973, 67, 253-262.

Enigk $K$, Dey-Hazra A: Zur Oberflächenstruktur und Funktion der äusseren Proteinhülle der Eies von Ascaris suum (Nematoda). (The surface and function of the protein layer of Ascaris suum eggs). Berl. Münch. tierärzl. Wschr. 1976, 89, 276-281.

Eriksen L: Host parasite relations in Ascaris suum infection in pigs and mice. DvSc thesis. Royal Veterinary and Agricultural University, Copenhagen 1981.

Eriksen L: Ascaris suum: Influence of egg concentration on in vitro development from embryonated eggs to infective stage. Proc. of the XIII symposium of the Scandinavian Society for Parasitology. Helsinki, Finland 1987, p. 53.

Eriksen L, Andersen $S$, Nielsen $K$, Pedersen A, Nielsen $J$ : Experimental Ascaris suum infection in pigs. Serological response, eosinophilia in peripheral blood, occurrence of white spots in the liver and worm recovery from the intestine. Nord. Vet.-Med. 1980, 32, 233-242.
Fairbairn D: Physiologic aspects of egg hatching and larval exsheatment in nematodes. In: L. A. Stauber (Editor): Host influence on parasite physiology. Rutgers University Press, New Brunswick, N. J. 1960, pp 50-64.

Jorgensen RJ: Isolation of Ascaris suum eggs for experimental purposes. Acta vet. scand. 1978, 19, 147-149.

Jorgensen RJ, Nansen $P$, Nielsen $K$, Eriksen $L$, Andersen $S$ : Experimental Ascaris suum infection in the pig. population kinetics following low and high levels of primary infection in piglets. Vet. Parasitol. 1975, 1, 151-157.

Martin RJ: The action of sodium benzylpenicillin at the bag region of Ascaris suum muscle. $\mathrm{J}$. Physiology 1981, 313, 58P.

Urban JFJr, Alizadeh H, Romanowski RD: Ascaris suum: development of intestinal immunity to infective second-stage larvae in swine. Experimental Parasitology 1988, 66, 66-77.

\section{Sammandrag}

Embryonering och infektivitet av Ascaris suum ägg. En jämförelse mellan ägg från maskuteri och ägg frän svinträck.

Ascaris suum ägg samlades från svinträck samt dissekerades från honmasker från samma svin. Ägg från bägge källor fick embryonera i $0.1 \mathrm{~N}$ $\mathrm{H}_{2} \mathrm{SO}_{4}$, i $1 \%$ formalin samt $\mathrm{i}$ vatten. Formalinkulturen utvecklades litet långsammare än de andra kulturena. Infektiviteten av ägg som isolerats från maskuteri och embryonerats i svavelsyra jämfördes med ägg från träck som embryonerats $i$ vatten. Med båda kulturena inokulerades en grupp av tio ungsvin, som slaktades 7 dagar senare. Larver räknades från lungorna och "white spots" från levrarna. Resultaten indikerar att de bägge typene av ägg var lika infektiva. På denna grund kan man för infektionsförsök rekommendera användandet av ägg dissekerade från maskar.

(Received October 24, 1989; accepted November 27, 1989).

Reprints may be requested from: Antti Oksanen, National Veterinary Institute, Regional Laboratory Oulu, P. O. Box 517, SF-90101 Oulu, Finland. 